\title{
Prevalence and etiology of nosocomial diarrhoea in children $<5$ years in Tikrit teaching hospital
}

S.B. Alrifai, ${ }^{1}$ A.Alsaadi, ${ }^{2}$ Y.A. Mahmood, ${ }^{3}$ A.A. Ali ${ }^{4}$ and L.A. Al-Kaisi ${ }^{5}$

$$
\begin{aligned}
& \text { معدَّل الانتشار وسبيَّات الإسهال المكتسب في المستشفيات لدى الأطفال دون } 5 \text { سنوات من العمر }
\end{aligned}
$$

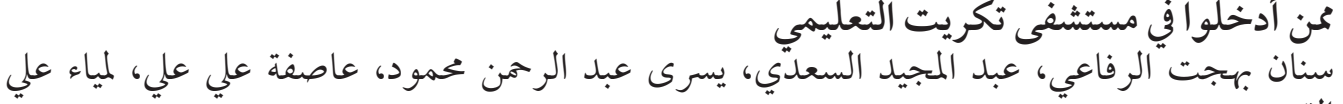

$$
\begin{aligned}
& \text { القيسي }
\end{aligned}
$$

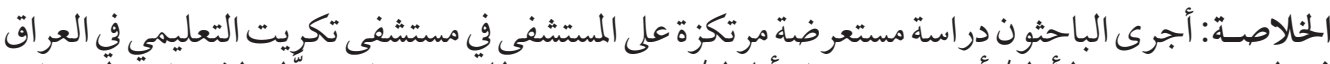

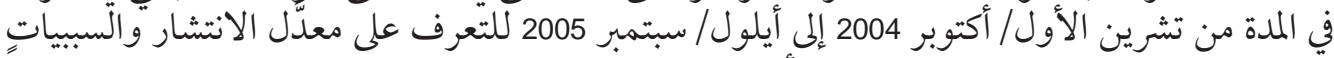

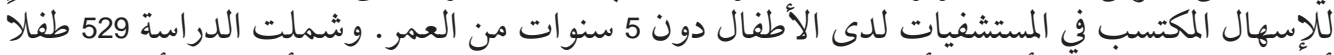

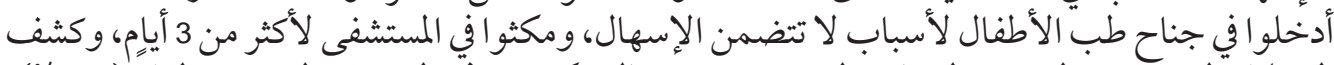

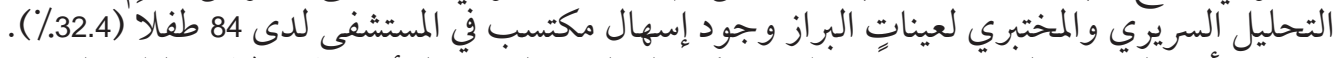

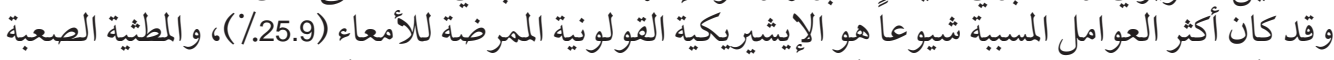

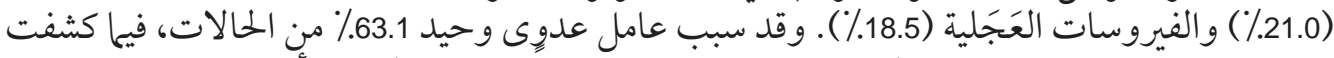

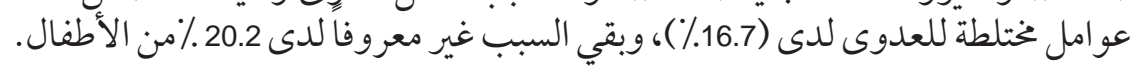

ABSTRACT A cross-sectional hospital-based study was carried out at Tikrit teaching hospital, Iraq, from October 2004 to September 2005, to identify the prevalence and etiology of nosocomial infectious diarrhoea among children under 5 years of age. Of 259 children admitted to the paediatric ward for reasons other than diarrhoea and hospitalized for more than 3 days, clinical and laboratory analysis of stool samples showed nosocomial diarrhoea in 84 children (32.4\%). The most common causative agents were enteropathogenic Escherichia coli $(25.9 \%)$, Clostridium difficile $(21.0 \%)$ and rotavirus (18.5\%). Single infectious agents caused $63.1 \%$ of the cases, while mixed infections were detected in $16.7 \%$; in $20.2 \%$ of children the cause remained unknown.

Prévalence et étiologie de la diarrhée nosocomiale chez des enfants de moins de 5 ans admis à l'hôpital universitaire de Tikrit

RÉSUMÉ Une étude transversale en milieu hospitalier a été réalisée à l'hôpital universitaire de Tikrit (Iraq) d'octobre 2004 à septembre 2005 afin de déterminer la prévalence et l'étiologie de la diarrhée infectieuse nosocomiale chez les enfants de moins de 5 ans. Sur 259 enfants admis dans le service de pédiatrie pour des raisons autres que la diarrhée et hospitalisés pendant plus de 3 jours, $84(32,4 \%)$ présentaient une diarrhée nosocomiale, comme l'ont montré l'analyse clinique et l'analyse en laboratoire des échantillons de selles. Les agents étiologiques les plus courants étaient Escherichia coli entéropathogène $(25,9 \%)$, Clostridium difficile $(21,0 \%)$ et le rotavirus $(18,5 \%)$. Un agent infectieux unique était responsable de $63,1 \%$ des cas, alors que des infections mixtes ont été détectées chez $16,7 \%$; pour $20,2 \%$ des enfants, la cause demeurait inconnue.

${ }^{7}$ Department of Medical Microbiology; ${ }^{3}$ Department of Medical Education, College of Medicine, University of Tikrit, Tikrit, Iraq (Correspondence to Y.A. Mahmood: Yusramahmood2003@yahoo.com).

${ }^{2}$ Department of Bacteriology and Immunology, College of Science, University of Kufa, Kufa, Iraq.

${ }^{4}$ Department of Microbiology; ${ }^{5}$ Department of Serology, Central Laboratory, Al-Kadhimiya Teaching Hospital, Baghdad, Iraq.

Received: 23/11/06; accepted: 02/05/07

المجلة الصحية لشرق المتوسط، منظمة الصحة العالمية، المجلد الخامس عشر، العدد 0، 9 +. 


\section{Introduction}

Nosocomial (hospital-acquired) diarrhoea is a common problem in hospitals, child care facilities and nursing homes [1]. In the United States, nosocomial diarrhoea has been reported to vary from less than 1 per 100 admissions among children to over 30 per 100 admissions for elderly adults. In developing countries, because diarrhoea is so common, even reasonable estimates are lacking [2].

Nosocomial diarrhoea can occur as a sporadic or an epidemic illness, and it can be due to infectious as well as noninfectious causes. As infectious diarrhoea is definitively diagnosed only when the bacterial or viral agent is identified, some cases of diarrhoea are never fully diagnosed $[2,3]$. The organisms causing nosocomial infections usually come from the patient's own body (endogenous flora). They also can come from contact with staff (cross-contamination), contaminated instruments and needles and the environment (exogenous flora). Because hospital stays are becoming shorter, patients are often discharged before the infection becomes symptomatic; thus a high proportion of nosocomial infections among hospitalized patients and from ambulatory care facilities become apparent only after patients are discharged. As a consequence, it is often difficult to determine whether the source of the organism causing infection is endogenous or exogenous [2].

Controlling the spread of nosocomial diarrhoea from contaminated food is an ongoing concern in hospitals and nursing homes. Frequently this is due to poorly trained staff using unsafe practices for the storage, preparation and handling of food. Moreover, because the quality of drinking water in countries with limited resources is often unsafe, controlling outbreaks of waterborne infectious diarrhoea are persistent problems [2].
This study in Iraq aimed to identify the prevalence and etiology of nosocomial infectious diarrhoea in children under 5 years of age admitted to Tikrit teaching hospital in Tikrit city.

\section{Methods}

A cross-sectional hospital-based study was carried out at Tikrit teaching hospital from October 2004 to the end of September 2005. The study included examination of 259 children (155 males and 104 females) aged 1-60 months who were admitted to the paediatric ward for reasons other than diarrhoea and stayed for more than 3 days. The Centers for Disease Control and Prevention (CDC) definition of nosocomial diarrhoea was used, i.e. acute onset of diarrhoea in a hospitalized patient with a period of at least 3 days of hospitalization prior to the onset of diarrhoea [3]. Neonates were excluded from the study because the circumstances of admission are different from other age groups of infants.

Stool samples were collected from each child in disposable clean containers and processed within 2 hours of collection. All samples were subjected to several diagnostic laboratory tests for detection of viral, bacterial, parasitic and fungal agents. The stool sample was given a general stool examination, with direct plating on blood and MacConkey agar and inoculation into enrichment media (peptone and tetrathionate). Identification of bacterial isolates was based on biochemical tests, use of the analytical profile index (Api20E) system and by specific agglutinating antisera. A portion of the stool sample was frozen for detection of Clostridium difficile toxins by enzymelinked immunosorbent assay (ELISA) and another portion was used for detection of human rotavirus antigen by the latex agglutination test. 
Swabs were taken from the paediatric ward environment, personal objects related to the children, relatives of the children and medical personnel in the ward. The presence of any of the traced bacterial isolates in stool was considered to indicate the causative agent of nosocomial diarrhoea when it was the only predominant bacterium that appeared in the culture [4], in addition to its presence in the ward (i.e. exogenous nosocomial infection). Those cultures with no clear predominance of a single bacterium were considered to be normal flora and the nosocomial diarrhoea was then due to causes other than bacterial. The evidence of a strong positive latex agglutination test for rotavirus, heavy fungus invasion present in the mycelium phase, and/or heavy parasitic infestation was considered to indicate the cause when no other causes were identified.

\section{Results}

A total of 259 hospitalized children under 5 years of age were examined. Of these, 84 children $(32.4 \%)$ were diagnosed with nosocomial diarrhoea. The data showed that majority were children $<12$ months of age $(67.9 \%$ of nosocomial diarrhoea cases), while $32.1 \%$ were aged $1-5$ years. The prevalence of nosocomial diarrhoea among males $(33.5 \%)$ was greater than among females $(30.8 \%)$ (Table 1$)$.

Among the children with nosocomial diarrhoea, there was no obvious causative agent detected in 17 children (20.2\%), while in 67 children $(79.8 \%)$, a variety of microbial causative agents were isolated and identified, with a total of 81 isolates.

The number of children with a single infectious agent causing the nosocomial diarrhoea was $53(63.1 \%$ of the total cases), while 14 children (16.7\%) had mixed infections of bacterial-bacterial, bacterial-parasitic or bacterial-viral elements.

The most commonly isolated microbial agent was enteropathogenic Escherichia coli (EPEC) in 21 cases $(25.9 \%)$, followed by $\mathrm{Cl}$. difficile in 17 cases $(21.0 \%)$ and rotavirus in 15 cases $(18.5 \%)$. These 3 agents were found in about two-thirds of isolates. Other microbial agents were detected in lower frequencies (Table 2).

The age group $>6-12$ months was the age group most affected by nosocomial diarrhoea (30.9\% of isolates), followed by age group $1-6$ months ( $25.9 \%$ of isolates). In both groups infections were predominately with EPEC, followed by rotavirus. The data showed that all the opportunistic

\begin{tabular}{|c|c|c|c|c|c|c|c|c|c|}
\hline \multirow{3}{*}{$\begin{array}{l}\text { Age group } \\
\text { (months) }\end{array}$} & \multicolumn{3}{|c|}{ Males } & \multicolumn{3}{|c|}{ Females } & \multicolumn{3}{|c|}{ Both sexes } \\
\hline & \multirow{2}{*}{$\begin{array}{c}\text { Total } \\
\text { No. }\end{array}$} & \multicolumn{2}{|c|}{ ND } & \multirow{2}{*}{$\begin{array}{c}\text { Total } \\
\text { No. }\end{array}$} & \multicolumn{2}{|c|}{ ND } & \multirow{2}{*}{$\begin{array}{c}\text { Total } \\
\text { No. }\end{array}$} & \multicolumn{2}{|c|}{ ND } \\
\hline & & No. & $\%$ & & No & $\%$ & & No & $\%$ \\
\hline $1-6$ & 38 & 14 & 36.8 & 26 & 8 & 30.8 & 64 & 22 & 34.4 \\
\hline$>6-12$ & 59 & 23 & 39.0 & 37 & 12 & 32.4 & 96 & 35 & 36.5 \\
\hline$>12-24$ & 17 & 7 & 41.2 & 15 & 4 & 26.7 & 32 & 11 & 34.4 \\
\hline$>24-36$ & 15 & 4 & 26.7 & 11 & 4 & 36.4 & 26 & 8 & 30.8 \\
\hline$>36-48$ & 15 & 2 & 13.3 & 9 & 3 & 33.3 & 24 & 5 & 20.8 \\
\hline$>48-60$ & 11 & 2 & 18.2 & 6 & 1 & 16.7 & 17 & 3 & 17.6 \\
\hline Total & 155 & 52 & 33.5 & 104 & 32 & 30.8 & 259 & 84 & 32.4 \\
\hline
\end{tabular}

المجلة الصحية لشرق المتوسط، منظمة الصحة العالمية، المجلد الخامس عشر، العدد 0، 9. ب 


\begin{tabular}{|c|c|c|c|c|c|c|c|c|}
\hline \multirow[t]{3}{*}{ Infectious agent } & \multicolumn{8}{|c|}{ Isolates by age group (months) } \\
\hline & \multirow{2}{*}{$\begin{array}{l}1-6 \\
\text { No. }\end{array}$} & \multirow{2}{*}{$\begin{array}{c}>6-12 \\
\text { No. }\end{array}$} & \multirow{2}{*}{$\begin{array}{c}>12-24 \\
\text { No. }\end{array}$} & \multirow{2}{*}{$\begin{array}{c}>24-36 \\
\quad \text { No. }\end{array}$} & \multirow{2}{*}{$\begin{array}{c}>36-48 \\
\text { No. }\end{array}$} & \multirow{2}{*}{$\begin{array}{c}>48-60 \\
\text { No. }\end{array}$} & \multicolumn{2}{|c|}{ Total } \\
\hline & & & & & & & No. & $\%$ \\
\hline \multicolumn{9}{|l|}{ Enteropathogenic } \\
\hline Escherichia coli & 6 & 9 & 3 & 2 & 1 & - & 21 & 25.9 \\
\hline Clostridium difficile & 4 & 4 & 3 & 2 & 3 & 1 & 17 & 21.0 \\
\hline Rotavirus & 4 & 6 & 3 & 1 & 1 & - & 15 & 18.5 \\
\hline Salmonella enteritidis & - & - & - & 2 & 1 & 2 & 5 & 6.2 \\
\hline Entamoeba histolytica & - & - & 2 & 2 & 1 & - & 5 & 6.2 \\
\hline \multicolumn{9}{|l|}{ Pseudomonas } \\
\hline aeruginosa & 2 & 2 & - & - & - & - & 4 & 4.9 \\
\hline Proteus mirabilis & 1 & 1 & - & - & - & - & 2 & 2.5 \\
\hline $\begin{array}{l}\text { Cryptosporidium } \\
\text { parvum }\end{array}$ & - & - & 1 & 1 & - & - & 2 & 2.5 \\
\hline Candida albicans & 2 & - & - & - & - & - & 2 & 2.5 \\
\hline \multicolumn{9}{|l|}{ Enterobacter } \\
\hline aerogenes & 1 & 1 & - & - & - & - & 2 & 2.5 \\
\hline Shigella flexneri & - & - & - & 1 & 1 & - & 2 & 2.5 \\
\hline Giardia lamblia & - & 1 & - & - & - & 1 & 2 & 2.5 \\
\hline Klebsiella oxytoca & 1 & - & - & - & - & - & 1 & 1.2 \\
\hline Citrobacter braakii & - & 1 & - & - & - & - & 1 & 1.2 \\
\hline Total & 21 & 25 & 12 & 11 & 8 & 4 & 81 & 100.0 \\
\hline
\end{tabular}

microorganisms (i.e. Pseudomonas aeruginosa, Proteus mirabilis, Citrobacter braakii, Klebsiella oxytoca, Enterobacter aerogenes) were detected in children aged $<1$ year, and they represented $15 \%$ of the total isolates (Table 2).

Bacterial infectious agents were the most common cause of infectious nosocomial diarrhoea, in 55 (67.9\%) isolates, viral causes in $15(18.5 \%)$, parasitic causes in $9(11.1 \%)$, and fungal infection in $2(2.5 \%)$ only.

Although EPEC was found in the largest number of cases, the most common single infectious agent causing infectious nosocomial diarrhoea was rotavirus in 14 children $(26.4 \%$ of 53 children with single infections), followed by EPEC in 10 children $(18.9 \%)$ and $\mathrm{Cl}$. difficile in 7 children $(13.2 \%)$. Other microbial agents were found in lower frequencies.
The most common type of mixed infection was bacterial-bacterial in 9 children (64.3\% of 14 children with mixed infections), with bacterial-parasitic infections in 4 children (29\%) and bacterial-viral infection detected in 1 child (7.1\%). The most common bacterial-bacterial combinations were EPEC (based on anti-EPEC antigen strains O26, O44, 0114, O125, 0142, O158I) $+\mathrm{Cl}$. difficile which was detected in 5 cases (35.7\%), EPEC (the remaining anti-EPEC antigen strains) $+C l$. difficile and E. histolytica $+\mathrm{Cl}$. difficile which were detected in 2 cases $(14.3 \%)$ each. Other combinations were detected in 1 case each $(7.1 \%)$.

Data from the patients' files showed that the antibiotics had been used in double or triple regimens including cefotaxime in $52(61.9 \%)$ of cases before the onset of diarrhoea. 


\section{Discussion}

Nosocomial diarrhoea is an acute diarrhoea defined by the place of infection (the hospital) and the time of onset (after 72 hours). The 3-day cut-off period is used in order to exclude microorganisms that might be acquired from the community and stay dormant in the body without clinical evidence [2,3].

The prevalence of nosocomial diarrhoea in developed countries varies from $1 \%$ to over $30 \%$ [2]. In developing countries this rate can be much higher due to lack of supervision, poor infection prevention practices, inappropriate use of limited resources and overcrowding of hospitals [2]. In our study, the prevalence was as high at $32.4 \%$. A study in northern Brazil reported a higher prevalence of nosocomial diarrhoea among children (about 40\%) [5], while in south India the prevalence was reported to be $20 \%$ among hospitalized children aged $<36$ months [6]. The difference in the prevalence is related to many factors such as hygiene practices, type of microorganisms endemic in the area and sanitation level of the hospitals.

Our data showed that a high percentage of nosocomial diarrhoea cases were in children $<1$ year of age $(67.9 \%)$. This prevalence is in agreement with other studies from Iraq [7-10] and also from Saudi Arabia [11]. A study in India found that the incidence of diarrhoea among children peaked at between 4 months and 2 years [12]. The nosocomial diarrhoea prevalence was higher among the 6-12-month age group than the 1-6-month group. These findings agree with other studies [10-12]. The increased incidence in this age is most likely the result of greater exposure to enteropathogens (as the use of solid food starts at this age) plus the immaturity of the immune system of the child, as well as the decline in passive immunity after age 6 months [11].

The sex distribution among the children in our study showed a slight preponderance of nosocomial diarrhoea in males compared with females. Similar findings have been reported in other studies in Iraq $[7,8,10]$.

In about $80 \%$ of the cases of nosocomial diarrhoea, an enteropathogen was found to be the causative agent. Similar findings were reported from northern Brazil (83\%) [11] and Iraq by Al-Jebouri (80.7\%) [10], Al-Khashab (77\%) [7] and Al-Marzoqi (75.5\%) [9]. In the $20 \%$ of cases where no pathogen was identified, about one-third of cases (6 children) were attributed to nasogastric feeding. The other two-thirds were attributed to antibiotic-associated diarrhoea [13], to unavailability of resources to diagnose diarrhoeagenic E. coli strains other than EPEC strains (e.g. enterotoxigenic E. coli) [3] or to noninfectious causes of nosocomial diarrhoea that may have been missed.

A single infectious agent was encountered in about $63 \%$ of total nosocomial diarrhoea cases, while mixed infections were found in almost $17 \%$ of cases (the cause remained unknown for the remainder). These results are similar to studies in India [6] and Turkey [14].

Of the total number of isolates, EPEC (25.9\%), Cl. difficile $(21.0 \%)$ and rotavirus (18.5\%) were the most common enteropathogens detected in nosocomial diarrhoea. Our results agree with an Indian study showing $29 \%$ for EPEC and $16.7 \%$ for rotavirus [3]. Other studies, however, have found rotavirus to be the most common pathogen causing infectious nosocomial diarrhoea among children [5,6]. Al-Jebouri [10], AlKhashab [7] and Al-Kaby [8] in Iraq also found that EPEC and rotavirus were among the most common agents causing infectious diarrhoea in children. Jindal et al. in India reported that $21.4 \%$ of cases of infectious diarrhoea were due to EPEC [15]. The results obtained regarding other bacterial agents were similar to those of many Iraqi researchers $[7-9,16,17]$. 
Our results for $\mathrm{Cl}$. difficile (found in $21.0 \%$ of isolates) are similar to those from Turkey (20.7\%) [14], whereas Uppal et al. in India found that $\mathrm{Cl}$. difficle was not a common cause of nosocomial diarrhoea [3]. Their results cannot be explained by prior treatment, as in both Uppal's and our study $\beta$-lactams were used for treatment before the onset of diarrhoea [3]. This difference may be because Uppal et al. detected the presence of only toxin A (enterotoxin) produced by enterotoxigenic strains of $\mathrm{Cl}$. difficile in the stool specimens of their patients and did not search for toxin B (cytotoxin). Some more recent reports have reported the outbreak of "toxin A negativetoxin B positive" $\mathrm{Cl}$. difficile strains in some tertiary care hospitals [18] and this may partially explain the low rate of $\mathrm{Cl}$. difficile in their study compared with ours. Also, the heavy use of antibiotics in double or triple regimens (in $62 \%$ of our children) before the onset of diarrhoea compared with Uppal et al.'s study [3]. This may predispose to higher rates of $\mathrm{Cl}$. difficile infection as $\mathrm{Cl}$. difficile-associated diarrhoea occurs significantly more frequently in patients given combined antibiotic treatment than in those given single antibiotic treatment [14], especially the combination of penicillins and cephalosporins [19]. $\mathrm{Cl}$. difficile-associated diarrhoea has also been reported following the administration of cefotaxime [20]. The wide use of cefotaxime in this study, whether alone or with other antibiotics, may have contributed to the high rate of $\mathrm{Cl}$. difficile-associated diarrhoea that we found.

Candida albicans was isolated as the only causative agent from 2 children $(2.4 \%)$; this low percentage agrees with Jindal et al. in India (1.3\%) [15]. Uppal et al., also in India, found that Can. albicans was the only causative agent in $6.6 \%$ of children with nosocomial diarrhoea [3]. In
Iraq, researchers found a higher prevalence of Can. albicans in infectious diarrhoea, for example Al-Marzoqi (9.5\%) [9] and AlJebouri (24\%) [10]. This is because they considered the presence of Can. albicans in stool as an opportunistic infection beside other pathogens, as well as the abuse of antibiotics as the reason for the overgrowth of this opportunistic pathogen. While in our study, pathogenicity was attributed to Candida isolates when they were present in the mycelial phase in direct stool examination [3], and when they were the only microorganism present in the stool sample without the presence of other pathogenic bacteria.

Rotavirus was the most common single infectious agent causing nosocomial diarrhoea. This agrees with Al-Khashab [7] and Al-Kaby [8] from Iraq, as well as Uppal et al. [3] and Kamalaratnam et al. from India [6], and Gusmao et al. from Brazil [5].

During the period of the current study, no clinical evidence of vibriosis due to Vibrio cholerae or food poisoning due to Staphylococcus aureus was found. Nor did we find other bacteria that are sometimes incriminated in nosocomial diarrhoea among children, such as Campylobacter jejuni and Yersinia enterocolitica [3].

\section{Conclusions}

The current study revealed a high prevalence of nosocomial diarrhoea in this hospital in Iraq, and the infectious causes were far greater than the non-infectious causes, with bacterial predominance among the infectious agents. Accordingly, we recommend routine general stool examination, stool culture/sensitivity and $\mathrm{Cl}$. difficile detection by ELISA methods for all patients with nosocomial diarrhoea to identify the causative agent involved. 


\section{References}

1. Lynch P. Infection prevention with limited resources: preventing nosocomial gastrointestinal infections. Chicago, ETNA Communications, 1997, 1:125-30.

2. Preventing infectious diarrhea and managing food and water services. In: Tietjen L, Bossemeyer D, Mclntosh M, eds. Infection prevention guidelines for healthcare facilities with limited resources. Baltimore, Maryland, Johns Hopkins Program for International Education in Gynecology and Obstetrics, 2003.

3. Horan TC, Andrus M, Dudeck MA. CDC/ NHSN surveillance definition of health care-associated infection and criteria for specific types of infections in the acute care setting. American journal of infection control, 2008, 36:309-32 (http://www. cdc.gov/ncidod/dhqp/pdf/nnis/NosInfDefinitions.pdf, accessed 23 April 2009).

4. Shin Woo Kim. Pseudomonas aeruginosa as a potential cause of antibioticassociated diarrhea. Journal of Korean medical sciences, 2001, 16:742-4.

5. Gusmão RH et al. Rotaviruses as a cause of nosocomial, infantile diarrhoea in northern Brazil: pilot study. Memorias do Instituto Oswaldo Cruz, 1995, 90(6):743-9.

6. Kamalaratnam $\mathrm{CN}$ et al. A prospective study of nosocomial enteric pathogen acquisition in hospitalized children in South India. Journal of tropical pediatrics, 2001, 47(1):46-9.

7. Al-Khashab FM. Microbiological study of enteric pathogens associated with persistent diarrhea among children under five years [MSc thesis]. Tikrit, Iraq, College of Medicine, University of Tikrit, 2001.

8. Al-Kaby FJ. A study on diarrhea in relation to malnutrition in children under 2 years in Baghdad [MSc thesis]. Baghdad, Iraq, College of Medicine, Al-Mustansiriya University, 2000.
9. Al-Marzoqi AH. Prevalence of rotavirus and other enteropathogens causing acute diarrhea in Hilla infants [MSc thesis]. Hilla, Iraq, College of Medicine, University of Babylon, 2004.

10. Al-Jebouri HS. Aetiology of diarrheal illness of children at Tikrit Teaching Hospital [MSc thesis]. Tikrit, Iraq, College of Education, University of Tikrit, 2001.

11. Al-Sekait MA. A study of factors affecting incidence of diarrhoeal disease in children under 5 years in Saudi Arabia. Saudi medical journal, 1988, 9(5):491-7.

12. Cicerello HG et al. High prevalence of rotavirus infection among neonates born at hospitals in Delhi, India: predisposition of newborns for infection with unusual rotavirus. Pediatric infectious disease journal, 1994, 13(8):720-4.

13. Pimentel RR. Antibiotic associated diarrhea. Cleveland, Ohio, Cleveland Clinic Foundation, 2003 [online article] (http:// www.clevelandclinicmeded.com/diseasemanagement/gastro/antibioticdiarrhea/ antibioticdiarrhea.htm, accessed $31 \mathrm{De}$ cember 2008).

14. Oguz $F$ et al. The role of $C$. difficile in childhood nosocomial diarrhea. Scandinavian journal of infectious diseases, 2001, 33(10):731-3.

15. Jindal $\mathrm{N}$ et al. A study of infective etiology of chronic diarrhea in children in Amristar. Journal of the Indian Medical Association, 1995, 93(5):169-70.

16. Al-Maali HM. A study of some aerobic diarrheal bacteria in children of Kerballa city and its sensitivity to some antibiotics [MSc thesis]. Ramadi, Iraq, College of Science, University of Anbar, 2004.

17. Mehdi LK. Infantile bacterial diarrhea in relation to the type of feeding $[\mathrm{PhD}$ thesis]. Baghdad, Iraq, College of Medicine, Saddam University, 1998. 
18. Al-Barrak $A$ et al. An outbreak of toxin A negative, toxin $B$ positive Clostridium difficile-associated diarrhea in a Canadian tertiary-care hospital. Canada communicable disease report, 1999, 25(7):65-9.

19. Bartlett JG. Antibiotic associated diarrhea. New England journal of medicine, 1999, 341:1690-1.
20. Green ST et al. Clostridium difficile induced colitis occurring during cefotaxime therapy. Ulster medical journal, 1985, 54:80-2.

Inter-country training on the Facilitator guide on the orientation and planning workshop for IMCl pre-service education, Cairo, Egypt, 25-30 July 2009

The above-mentioned three-day training course aimed at building capacity in countries in the Region in the use of the Facilitator Guide on the Practical Orientation and Planning Workshop for IMCI Pre-service Education. It also served as an opportunity to finalize the Guide. It was attended by 19 participants, including senior teaching staff of 8 academic institutions of 5 countries in the Region (Egypt, Jordan, Pakistan, Sudan and Yemen), staff of ministries of health, UMICEF and WHO staff at $H Q$, regional and country level.

During the workshop, in addition to the Guide, other elements of the regional package for $\mathrm{IMCl}$ pre-service education were used, such as the e-lectures on the "Management of the sick child age 2 months up to 5 years", "Management of the sick young infant up to 2 months" and "IMCl strategy".

All the above materials of the $\mathrm{IMCl}$ pre-service education package developed by the WHO Regional Office, including the Guide on the Evaluation of $\mathrm{IMCl}$ Pre-service Education and the $\mathrm{IMCl}$ question bank for student assessment, are expected to be ready in their final format before the end of 2009. 